\title{
Gender and parity: Potential sources of variance in ACTH-induced memory reactivation in weanling rats
}

\author{
CHARLES F. MACTUTUS \\ University of Kentucky, Lexington, Kentucky \\ GREGORY HARPER \\ Kent State University, Kent, Ohio \\ ROSEMARIE M. BOOZE \\ University of Kentucky, Lexington, Kentucky \\ and \\ DAVID C. RICCIO \\ Kent State University, Kent, Ohio
}

\begin{abstract}
The effect of ACTH on retention of Pavlovian fear conditioning was investigated in weanling rats. No influence of ACTH on memory was observed in male and female pups of primiparous dams. Male offspring of multiparous dams displayed increased retention with the ACTH reactivation treatment, as indexed by three behavioral measures. Female offspring of multiparous dams, as well as those of primiparous dams, demonstrated linear ACTH dose-dependent increases in vacillatory activity, but no facilitation of memory. Collectively, the present data extend the generality of ACTH-induced memory reactivation to include the attenuation of infantile amnesia, but also suggest that this effect is constrained by gender of the offspring and maternal parity.
\end{abstract}

Considerable attention has been focused on the role of hormones in influencing learning and memory processes (Martinez, Jensen, Messing, Rigter, \& McGaugh, 1981; McGaugh, 1983; Richardson, Riccio, \& Devine, 1984; Santucci, Riccio, \& Treichler, 1989). Several lines of evidence now support the position that stress-related hormones may re-establish a previously acquired fear response (Richardson \& Riccio, 1991). For example, the deficit in performance at intermediate retention intervals after active avoidance training (i.e., the Kamin effect) can be eliminated by administration of ACTH (Klein, 1972). Posttraining ACTH facilitates retention of passive avoidance in a dose-dependent manner (inverted $U$ ) (Gold \& Van Buskirk, 1976). Experimentally induced retrograde amnesia can be reversed by administration of ACTH shortly prior to testing (Mactutus, Smith, \& Riccio, 1980; Rigter \& Van Riezen, 1975). Although developmental retention loss (i.e., infantile amnesia) may also

This research was supported in part by grants from the National Institutes of Health Sciences (ES06259 and DA09160 to C.F.M.; AG 10747 and DA06638 to R.M.B.; and MH37535 to D.C.R.) and the Commonwealth of Kentucky (541119 to C.F.M.). We thank Regina M. Sullivan and James T. Concannon for comments on earlier drafts of this paper. Correspondence should be addressed to C. F. Mactutus, Pharmacology and Experimental Therapeutics, College of Pharmacy, Rose Street, University of Kentucky, Lexington, KY 40536-0082 (email: cfmactl@ukcc.uky.edu). be attenuated when ACTH is paired with Pavlovian fear cues as a mid-retention-interval reinstatement (Haroutunian \& Riccio, 1979), no evidence exists that ACTH treatment alone can attenuate developmental retention loss when given shortly prior to testing. Thus, despite its apparent generality, the young developing pup may represent a boundary condition for the facilitatory effect of ACTH on retention processes. Even though the preweanling rat does not clearly display the diurnal rhythmicity of the mature hypothalamic-pituitary-adrenal axis (Ader, 1969), it is sufficiently mature by the 3 rd week of life to show a significant corticosterone response to stress (i.e., $200 \%-400 \%$ ) (Sapolsky \& Meaney, 1986). Moreover, other treatments that may similarly mimic internal "arousal" cues, such as noncontingent footshock, can function as effective reactivation agents in weanling rats originally trained at 16 days of age (Spear \& Parsons, 1976). Accordingly, we examined the efficacy of ACTHinduced memory reactivation in weanling rats that had been trained 7 days previously.

Because many, if not all, previous studies of "reminder" phenomena with young rats have employed only male subjects, or have failed to look for any gender differences, we have specifically examined the influence of gender on ACTH-induced reactivation of memory. Since preliminary data also suggested a role of parity of the dam in the responsiveness of the pups to the ACTH treatment, two experiments were conducted: one with the off- 
spring of primiparous dams, and the other with the offspring of multiparous dams.

\section{METHOD}

\section{Subjects}

The animals used in the first experiment consisted of the offspring of 8 nulliparous Sprague-Dawley females obtained from the Holtzman Company (Madison, WI) and bred in our colony. Although nulliparous at the time they were assigned to the experiment, these females will hence be designated "primiparous" in accord with their state of parity in the present experiment. Litters were culled at 1 day of age to 4 pups of each gender. All litters were maintained under conditions of ad-lib food and water, a 16:8-h light:dark cycle, and controlled temperature $\left(20^{\circ} \pm 2^{\circ} \mathrm{C}\right)$. The subjects for the second experiment were the offspring of nine multiparous Sprague-Dawley dams (Holtzman Company, Madison, WI), that were bred and maintained as in the first experiment.

\begin{abstract}
Apparatus
The apparatus consisted of an aluminum and Plexiglas black-white shuttlebox divided into two equal-sized compartments, each $25.0 \times 18.0 \times 23.0 \mathrm{~cm}$. These compartments were separated by a $0.5-\mathrm{cm}$ partition with an opening of $6.8 \times 11.2 \mathrm{~cm}$ that could be blocked by lowering a door. A single $15-\mathrm{W}$ incandescent bulb, suspended $40 \mathrm{~cm}$ above the center of the white compartment, provided the only source of illumination in the experimental room. The floor of the shuttlebox consisted of $0.3-\mathrm{cm}$-diameter grids spaced $1.3 \mathrm{~cm}$ center to center. The grids on the black side were connected to a fixed-impedance shock source through a Foringer scrambler (Model SC-901). This circuit was calibrated to deliver a 150-V, 1.0sec shock when triggered manually by a silent switch. To add to the distinctiveness of the two compartments, a $0.15-\mathrm{cm}$ aluminum plate covered the grids in the white compartment.
\end{abstract}

\section{Procedure}

A randomized blocks design was employed, with litter as the blocking factor, in which three treatment and two gender conditions were represented. Three pups of each gender, randomly chosen from each litter, received Pavlovian discriminated fear conditioning in the two-compartment shuttlebox at 16 days of age. All animals were trained between 10:00 a.m. and 4:00 p.m. To further control for the influence of time of day, 1 subject was trained/ tested from each factorial cell during the same time block prior to training/testing a 2 nd subject from any design cell. Training consisted of a $60-\mathrm{sec}$ period in the illuminated compartment without shock, followed by a 60 -sec session in the dark, during which each pup received three shocks ( $150-\mathrm{V}, 1-\mathrm{sec}$, fixed-impedance shock delivered at 15,30 , and $45 \mathrm{sec})$. The door between compartments was down during the fear conditioning procedure. Training 16day-old rats in this paradigm provides evidence of robust fear conditioning (mean $\pm S E M$ : cross-through latency $=1,165 \pm 258 \mathrm{sec}$, TTW $=1,199 \pm 250 \mathrm{sec}$, number of cross-through responses $=1.4$ \pm 0.8 ) through a 24 -h retention interval (Mactutus, Concannon, \& Riccio, 1982).

Retention of Pavlovian fear conditioning was assessed with a passive avoidance test at 23 days of age (i.e., a 7 -day retention interval). For each litter, 1 pup of each gender was administered a single s.c. injection of either $0.9 \%$ saline, $0.8 \mathrm{IU}-$, or $8.0 \mathrm{IU}-\mathrm{ACTH}$ (ACTHAR gel, Armour Pharmaceutical Company, Kanakee, IL) $30 \mathrm{~min}$ prior to testing. These doses of ACTH were chosen on the basis of our prior work with adult animals and a small preliminary study that failed to show any significant reactivation effects in weanling-age rats with doses of $0.2,0.4$, or $0.8 \mathrm{IU} \mathrm{ACTH}$, but the factor of parity was not recorded or controlled. Three dependent measures were recorded throughout an 1,800 -sec test session: (1) the initial latency to cross through into the dark compartment, (2) the number of cross-through responses, and (3) the total time spent in the white "safe" compartment (TTW). The cross-through latency and total time measures were collected to provide traditional and conservative indices of retention, respectively. The number of cross-through responses was monitored as an index of hormone-induced changes in vacillatory activity.

\section{Statistical Methods}

Analysis of variance (ANOVA) was chosen over nonparametric procedures, because the interaction term of ACTH treatment and gender was of greatest interest. Retention test data were either $\log _{10}(X+1)$ (time scores) or square root $(X+0.5)$ (frequency score) transformed. For each experiment, the data were analyzed by randomized-block-design ANOVAs with litter as the blocking factor (Denenberg, 1976). The conventional significance level of $p \leq .05$ was employed. Computational procedures utilized the BMDP statistical software package (1993).

\section{RESULTS}

\section{Offspring of Primiparous Dams}

As is illustrated in the top panel of Figure 1, neither dose of ACTH served to facilitate retention of male or female pups of primiparous dams as indexed by crossthrough response latency $[F(2,35)<1.00]$. The more conservative retention index, total time spent in the white "safe" compartment (TTW; center panel of Figure 1) also failed to yield any evidence of ACTH-induced memory reactivation for either gender grouping $[F(2,35)<1.00]$. That the ACTH treatment was, however, effective in increasing the "arousal" state theoretically necessary to provide a salient retrieval cue is suggested by a trend for increased vacillatory activity in the female pups (bottom panel of Figure 1) as a function of ACTH dose [linear trend, $F(1,35)=3.52, p \leq .07]$.

\section{Offspring of Multiparous Dams}

In contrast to the data from the primiparous offspring, the data from the multiparous dams indicated that the administration of ACTH to offspring of multiparous dams shortly prior to testing served as an effective memory reactivation treatment (top panel of Figure 2). A significant increase in cross-through latency was observed as a function of ACTH treatment $[F(2,40)=3.46, p \leq .04]$; however, a significant treatment by gender interaction $[F(2,40)=4.51, p \leq .02]$ with a linear treatment by gender component $[F(1,40)=8.70, p \leq .005]$ indicated that the males and females were differentially affected by ACTH administration. Specific pairwise contrasts indicated that this facilitation of retention was restricted to the male pups; both the low [0.8 IU ACTH, $F(1,40)=$ $10.00, p \leq .003]$ and high [8.0 IU ACTH, $F(1,40)=$ $11.98, p \leq .001]$ ACTH-dosed animals displayed longer latencies than saline controls. A similar pattern of ACTH-induced memory facilitation was observed on the more conservative TTW index (center panel of Figure 2) $[F(2,40)=3.47, p \leq .04]$ and was accompanied by evidence suggesting a gender difference in retention $[F(1,40)=3.20, p \leq .08]$, but no interactions of gender with treatment were noted. As with the traditional measure, both groups of ACTH-dosed males demonstrated significantly greater time spent in the white compart- 
OFFSPRING OF PRIMIPAROUS DAMS
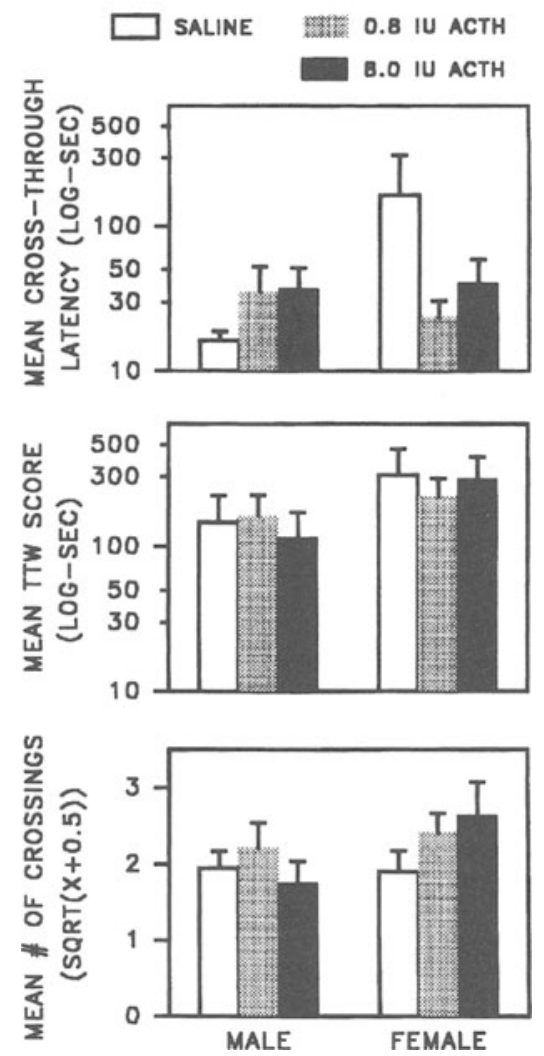

Figure 1. Mean ( $(\boldsymbol{S E M})$ passive avoidance test scores of male and female offspring of primiparous dams are plotted as a function of reactivation treatment administered $0.5 \mathrm{~h}$ prior to testing. Pavlovian fear conditioning was given 7 days eartier at 16 days of age. No significant effect of either ACTH treatment was detectable on measures of cross-through latency (top panel) or total time spent in the white compartment (center panel). An ACTH-induced dose-dependent increase in cross-through responding was, however, apparent in the female pups (bottom panel).

ment than did saline-injected controls [8.0 IU ACTH, $F(1,40)=4.44, p \leq .04$; and $8.0 \mathrm{IU}$ ACTH, $F(1,40)=$ $4.27, p \leq .05]$, whereas no effect of ACTH treatment was observed in the females $[F \mathrm{~s}(1,40)<2.50, p s>.10]$. The ACTH treatment also appeared to influence the number of cross-through responses executed during the 1,800$\mathrm{sec}$ test session (bottom panel of Figure 2). Evidence for a significant treatment by gender interaction [linear, $F(1,40)=5.08, p \leq .03$ ] indicated that an ACTH dose-related decrease in vacillatory activity of the male pups occurred at the same time that a dose-related increase in vacillatory activity was noted for the female pups.

\section{DISCUSSION}

The present findings suggest that the efficacy of ACTH-induced memory reactivation may be extended to include the attenuation of infantile amnesia. It is also notable that other recent data have further extended the generality of the cuing function of $\mathrm{ACTH}$ to include appetitive discrimination performance (Stoller \& Stoller, 1993) and to partially mediate the punishment augmentation effect of shock treatment (Anderson, 1993).

Prior difficulties in obtaining significant memory reactivation in preweanling rats with other agents (Spear \& Parsons, 1976) as well as aspects of the present data suggest the presence of some important boundary conditions for the reactivation phenomenon. This conclusion is further supported by the observations demonstrating the inability of hormonal treatments by themselves (i.e., not paired with Pavlovian cues) to facilitate retention over 24-h (Gold, Murphy, \& Cooley, 1982) or 7-day intervals (Haroutunian \& Riccio, 1979) - suggesting that the modulation of learning and memory processes in preweanling/weanling rats is more transient than is commonly observed in adult animals (Mactutus et al., 1980; Rigter \& Van Riezen, 1975). Whether such age-dependent effects are related to the maturation of diurnal cyclicity of
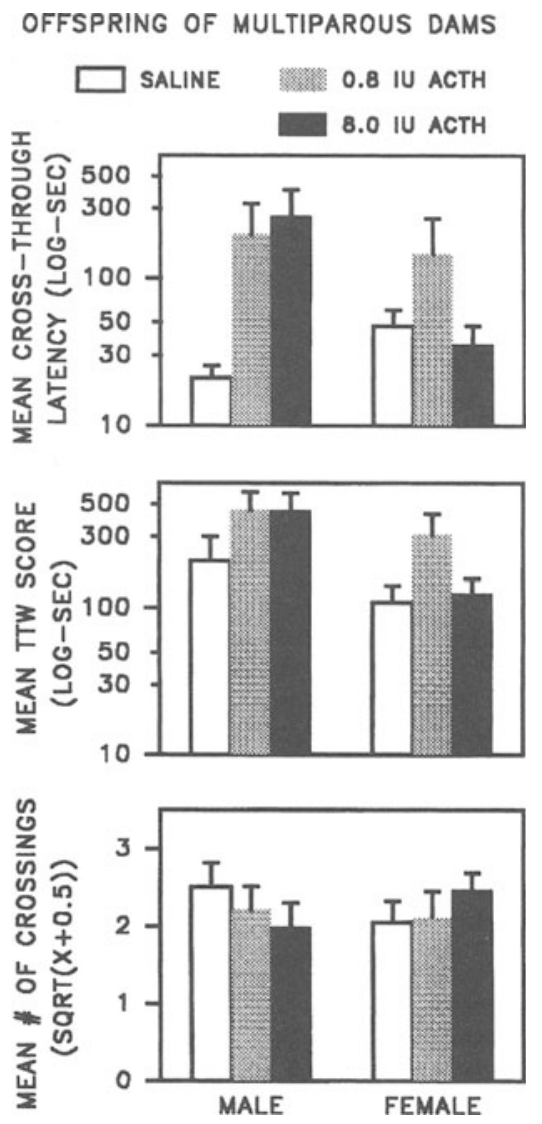

Figure 2. Mean ( $\pm S E M$ ) passive avoidance test scores of male and female offspring of multiparous dams are portrayed as a function of reactivation treatment administered $0.5 \mathrm{~h}$ prior to testing. Both ACTH reactivation treatments produced significantly longer latency scores (top panel) and longer total time spent in the illuminated compartment (center panel) in male, but not female, pups. A linear treatment by gender interaction for the number of cross-through responses (bottom panel) suggested that the vacillatory activity of male offspring was depressed, whereas that of the female offspring was increased by the ACTH treatment in a dose-dependent manner. 
the pituitary-adrenal axis was not addressed in the present studies, although it has been clearly established that passive avoidance retention of adult rats is modulated by circadian periodicity (Holloway \& Wansley, 1973).

The present data, however, do indicate two factors that may obscure the detection of an ACTH "reminder" effect in the developing rat. First, the evidence for a significant effect of ACTH on retention was restricted to male pups. Although the ACTH treatment also increased "arousal" of the female pups, as indicated by increased vacillatory activity, no facilitation of retention performance was observed. Thus, although ACTH treatment provided the theoretically necessary internal cues for facilitated memory retrieval, no such effect was detectable in the female offspring. These findings support the contention that inhibitory behavior involves gender-specific as well as agespecific (Stehouwer \& Campbell, 1980) and speciesspecific (Bolles, 1970) response determinants.

Second, the lack of any detectable influence of ACTH on retention performance of the pups of primiparous dams suggests another source of variability that deserves control in future investigations. At this time, we can offer only a speculative account of how parity may influence drug responsiveness. It has been reported that the mothering of multiparous dams is not as contingent upon pupproduced cues as is that of the primiparous dams (Wright, Bell, Schreiber, Villescas, \& Conely, 1977). A change in maternal behavior of multiparous dams has also been shown to result from differential treatment (handling) of the offspring of their first litter (Villescas, Bell, Wright, \& Kufner, 1977). With increasing maternal parity, there are marked reductions in neural sensitivity to opioids, reflected in measures of maternal behavior as well as suckling-induced stimulation of prolactin (Mann \& Bridges, 1992). Collectively, these observations suggest that experiential factors play an important role in maternal care. If maturation of the offspring's pituitaryadrenal system were modified by maternal behavior, differential responsiveness to the hormonal reactivation episode could be a consequence of that change. Direct observations of maternal behavior were not obtained in this study, but body weights may provide an indirect evaluation of care. Although growth curves were not available, the mean body weight $( \pm S E M)$ data at 24 days of age (male and female offspring of primiparous dams, $43.9 \pm 8.8$ and $41.7 \pm 9.8 \mathrm{~g}$ vs. male and female offspring of multiparous dams, $57.0 \pm 10.7$ and $53.4 \pm 9.1 \mathrm{~g}$ ) suggested that differential maternal care was indeed present.

To the best of our knowledge, there is only one other experimental study on the effects of maternal parity on drug responsiveness of the offspring (Ristine \& Spear, 1982). However, contrary to the influence of maternal parity in the present study, a dose-dependent increase was found in the suckling response of weanling rat pups to the serotonergic antagonist metergoline in offspring of primiparous dams, with no detectable effect on the offspring of multiparous dams. In the broader context of the early experience literature, there is another notable example of an alteration in drug effects based on neonatal experience. Specifically, a reduction in $d$-amphetamine toxicity in adulthood was observed when early handling (e.g., Denenberg, 1964) had been followed by immediate return to the mother as opposed to having been followed by one of several alternatives: Pups returned to the nest without the mother for an additional hour; pups separated from the mother only for $1 \mathrm{~h}$, or pups unhandled (Schreiber et al., 1977).

In summary, the present data extend the generality of ACTH-induced memory reactivation to include the attenuation of infantile amnesia. However, it is also clear that constraints may be placed on this generality by two potential sources of variance: offspring gender and maternal parity.

\section{REFERENCES}

ADER, R. (1969, March 14). Early experiences accelerate maturation of the 24-hour adrenocortical rhythm. Science, 163, 1225-1226.

ANDERSON, D. C. (1993). Does ACTH mediate the punishment-intensification effect of prolonged, fixed-duration shock treatment? Psychobiology, 21, 43-49.

BOLLES, R. C. (1970). Species-specific defense reactions and avoidance learning. Psychological Review, 77, 32-48.

DenenBerG, V. H. (1964). Critical periods, stimulus input and emotional reactivity: A theory of infantile stimulation. Psychological Review, 71, 335-351.

DENENBERG, V. H. (1976). Statistics and experimental design for behavioral and biological researchers: An introduction. Washington, DC: Hemisphere.

Gold, P. E., Murphy, J. M., \& Cooley, S. (1982). Neuroendocrine modulation of memory during development. Behavioral \& Neural Biology, 35, 277-293.

Gold, P. E., \& VAN BuSKIRK, R. (1976). Enhancement and impairment of memory processes with posttrial injections of adrenocorticotrophic hormone. Behavioral Biology, 16, 287-400.

Haroutunian, V., \& Riccio, D. C. (1979). Drug-induced "arousal" and the effectiveness of CS exposure in the reinstatement of memory. Behavioral \& Neural Biology, 26, 115-120.

Holloway, F. A., \& Wansley, R. A. (1973, April 13). Multiple retention deficits at periodic intervals after passive avoidance learning. Science, 180, 208-210.

KLEIN, S. B. (1972). Adrenal-pituitary influences in reactivation of avoidance memory in the rat after intermediate intervals. Journal of Comparative \& Physiological Psychology, 79, 341-359.

Mactutus, C. F., Concannon, J. C., \& Riccio, D. C. (1982). Nonmonotonic age changes in susceptibility to hypothermia-induced retrograde amnesia in rats. Physiology \& Behavior, 28, 939-943.

Mactutus, C. F., SMith, R. L., \& Riccio, D. C. (1980). Extending the duration of ACTH-induced memory reactivation in an amnesic paradigm. Physiology \& Behavior, 24, 541-546.

MANN, P. E., \& Bridges, R. S. (1992). Neural and endocrine sensitivities to opioids decline as a function of multiparity in the rat. Brain Research, 580, 2241-2248.

Martinez, J. L., JR., Jensen, R. A., Messing, R. B., Rigter, H., \& MCGAUGH, J. L. (Eds.) (1981). Endogenous peptides and learning and memory processes: Part I. ACTH \& MSH (pp. 5-196). New York: Academic Press.

McGaugh, J. L. (1983). Hormonal influences on memory. Annual Review of Psychology, 34, 297-323.

Richardson, R., \& Riccio, D. C. (1991). Memory processes, ACTH, and extinction phenomena. In L. Dachowski \& C. F. Flaherty (Eds.), Current topics in animal learning: Brain, emotion, and cognition (pp. 1-23). Hillsdale, NJ: Eribaum. 
Richardson, R., Riccio, D. C., \& Devine, L. (1984). ACTH-induced recovery of extinguished avoidance responding. Physiological Psychology, 12, 184-192.

Rigter, H., \& VAN RiEzen, H. (1975). Anti-amnestic effect of ACTH 4-10: Its independence of the nature of amnestic agent and the behavioral test. Physiology \& Behavior, 14, 563-566.

Ristine, L. A., \& SPEAR, L. P. (1982, October). Parity of the maternal female influences suckling of weanling age offspring. Paper presented at the meeting of the International Society for Developmental Psychobiology, Minneapolis.

Santucci, A. C., Riccio, D. C., \& Treichler, F. R. (1989). Role of ACTH in recovery from retrograde amnesia induced by hypothermia in rats. Behavioral Neuroscience, 103, 217-224.

SAPOLSKY, R. M., \& MEANEY, M .J. (1986). Maturation of the adrenocortical stress response: Neuroendocrine control mechanisms and the stress hyporesponsive period. Brain Research Reviews, 11, 65-76.

Schreiber, H. L., Bell, R. W., KufNer, M., \& Villescas, R. (1977). Maternal behavior: A determinant of amphetamine toxicity in rats. Psychopharmacology, 52, 173-176.
Spear, N. E., \& Parsons, P. J. (1976). Analysis of a reactivation treatment: Ontogenetic determinants of alleviated forgetting. In D. L. Medin, W. A. Roberts, \& R. T. Davis (Eds.), Processes of animal memory (pp. 135-165). Hillsdale, NJ: Erlbaum.

Stehouwer, D. J., \& CAmpbell, B. A. (1980). Ontogeny of passive avoidance: Role of task demands and development of speciestypical behavior. Developmental Psychobiology, 13, 385-398.

StOller, W. L., \& STOLLeR, R. A. V. (1993). Effects of adrenocorticotropic hormone on appetitive discrimination performance in rats. Psychobiology, 21, 272-276.

VillesCas, R., BELl, R. W., WRight, L., \& KufNer, M. (1977). Effects of handling on maternal behavior following return of the pups to the nest. Developmental Psychobiology, 10, 323-329.

Wright, L., Bell, R. W., Schreiber, H. L., Villescas, R., \& CoNELY, L. (1977). Interactive effects of parity and pup stress in maternal behavior. Developmental Psychobiology, 10, 331-337.

(Manuscript received November 7, 1994; revision accepted for publication May 15,1995 .) 